\title{
Proposta de um instrumento digital para a verificação do comportamento de motoristas
}

\author{
Amanda Bifano Balbinot \\ Programa de Pós-Graduação \\ em Informática na Educação/ \\ UFRGS. Porto Alegre/ RS - Brasil \\ ambalbinot@gmail.com
}

\author{
Milton Antônio Zaro \\ Programa de Pós-Graduação \\ em Informática na Educação / \\ UFRGS. Porto Alegre/ RS - Brasil \\ zaro@ibtec.org.br
}

\begin{abstract}
Resumo Este artigo tem por objetivo apresentar o desenvolvimento e a aplicação de um jogo digital de trânsito, destinado a auxiliar na área de educação e segurança de trânsito. $O$ interesse principal deste trabalho é a investigação e o desenvolvimento de um instrumento, jogo, que permita identificar e avaliar a ocorrência de comportamentos de risco em condutores com habilitação categoria B. Está fundamentado, em trabalhos que caracterizam o cometimento de erros, lapsos e violações que ensejam o envolvimento em acidentes de trânsito, tendo como base o Driver Behavior Questionnaire (DBQ) e em dados estatísticos sobre as infrações mais cometidas. A identificação de forma precoce de fatores preditores de comportamentos de risco no trânsito tem sua relevância por corroborar para a efetividade das intervenções preventivas na área de trânsito.
\end{abstract}

Palavras-Chave: Jogo digital de trânsito, comportamento de risco, motoristas.

\begin{abstract}
This article aims to present the development and implementation of a digital game traffic, to assist in education and traffic safety. The main interest of this work is research and development of an instrument, play, to identify and evaluate the occurrence of risk behaviors in drivers with license category $B$. It is based on studies that characterize the commission of errors, lapses and violations that lead to involvement in traffic accidents, based on the Driver Behavior Questionnaire (DBQ) and statistics on more infractions committed. The identification of an early predictors of risk behavior in traffic has its relevance by support for the effectiveness of preventive interventions in the area of transit
\end{abstract}

Keywords: Digital game traffic, risk behavior, drives. 


\section{Introdução}

Historicamente, o trânsito inicia com a utilização dos meios de transporte pelo homem, o qual precisou aprender uma nova forma de se locomover e se relacionar, o que deu origem ao condutor [13]. Os problemas de trânsito acompanham a humanidade ao longo do tempo. No Brasil, segundo o Instituto de Pesquisas Econômicas Aplicadas [IPEA], os acidentes de trânsito,apresentam custos sociais, ambientais, psicológicos e financeiros, destacando-se a demanda:

- por leitos hospitalares;

- o impacto psicológico em acidentados e familiares;

- as faltas ao trabalho;

- as indenizações e

- os gastos materiais [6].

Conforme dados da Companhia de Engenharia de Tráfego de São Paulo [CET-SP], as infrações ligadas ao comportamento lideram as multas de trânsito em 2007 evidenciando principalmente:

- excesso de velocidade,

- uso de celular ao volante,

- ultrapassagem de semáforo vermelho e

- dirigir sem cinto de segurança [12].

Investir na formação de condutores parece ser uma medida importante, para a redução deste problema. A aprendizagem veicular exige do aprendiz a manifestação das capacidades e aquisições de habilidades motoras, sensoriais, funções cognitivas, além de informações sobre o trânsito, suas implicações técnicas, preventivas, defensivas e punitivas. As funções cognitivas, quando relacionadas à direção veicular incluem "a memória e atenção, a avaliação sistemática do ambiente e outras habilidades visuoespaciais, verbais e de processamento de informações, tomada de decisões e resolução de problemas [9]. No entanto, nos deparamos muitas vezes com a falta de uma cultura educacional que relacione as deficiências dos condutores com as necessidades da educação para o trânsito. Neste cenário, a utilização de jogos digitais podem se configurar em instrumentos, que permitem a construção de ambientes os quais estimulem vários sentidos como visuais, auditivos e motores, favorecendo o processo de aprendizagem e propiciando uma vivencia que se aproxime do realidade.

Conforme Diógenes [4], no Brasil, a maioria dos planos, programas e ações voltados para a segurança viária ainda são formulados a partir da experiência e da intuição dos técnicos. Os programas de direção defensiva existen- tes $^{1}$ em sua grande maioria são teóricos, com conceitos sobre atitudes defensivas. As avaliações nesses cursos são compostas por questões de múltipla escolha sobre conceitos.

Para Backlund [1], no processo de formação de condutores, os instrutores de trânsito utilizam diversos instrumentos, tais como papel, caneta, vídeos, imagens e computadores. Entretanto, muitas vezes, esses instrumentos não abrangem áreas específicas do ato de dirigir, como o tempo de reação e a atenção, as quais poderiam predizer aspectos sobre as ações do sujeito ao conduzir um veículo. Os autores consideram que simuladores de condução, tornam-se ferramentas úteis, proporcionando experiências em simulações de condições reais de trânsito, permitindo ao jogador interagir virtualmente com o trânsito e acompanhar seu desempenho. Evidenciando assim, a aplicabilidade de jogos área de educação e segurança no trânsito.

Desta forma, este trabalho pretende fundamentar a construção de um jogo digital de trânsito para verificar os procedimentos realizados pelo jogador frente a situações específicas de trânsito, identificando comportamentos de risco em condutores. Realizou-se uma avaliação dos principais comportamentos relacionados ao risco de acidentes, por meio de pesquisas realizadas em diversos países, com a aplicação do QCM, e conjuntamente com o levantamento das infrações mais cometidas no trânsito em Porto Alegre.

Objetivando-se assim, com a aplicação deste instrumento, auxiliar na avaliação de condutores, disponibilizar um feedback para sua autoavaliação e fornecer informações para programas voltados a área de trânsito. Este instrumento foi utilizado com condutores, em Centros de Formação de Condutores [CFCs].

Para fundamentar e estruturar o desenvolvimento do jogo digital de trânsito, levantou-se alguns aspectos considerados fundamentais para chegar-se ao Comportamento de risco de condutores. O esquema a seguir na Figura 1 apresenta esta estruturação, que possibilitou chegar a classificação final do jogo.

\footnotetext{
${ }^{1}$ Exemplos disponíveis em sites dos DETRANs.
} 


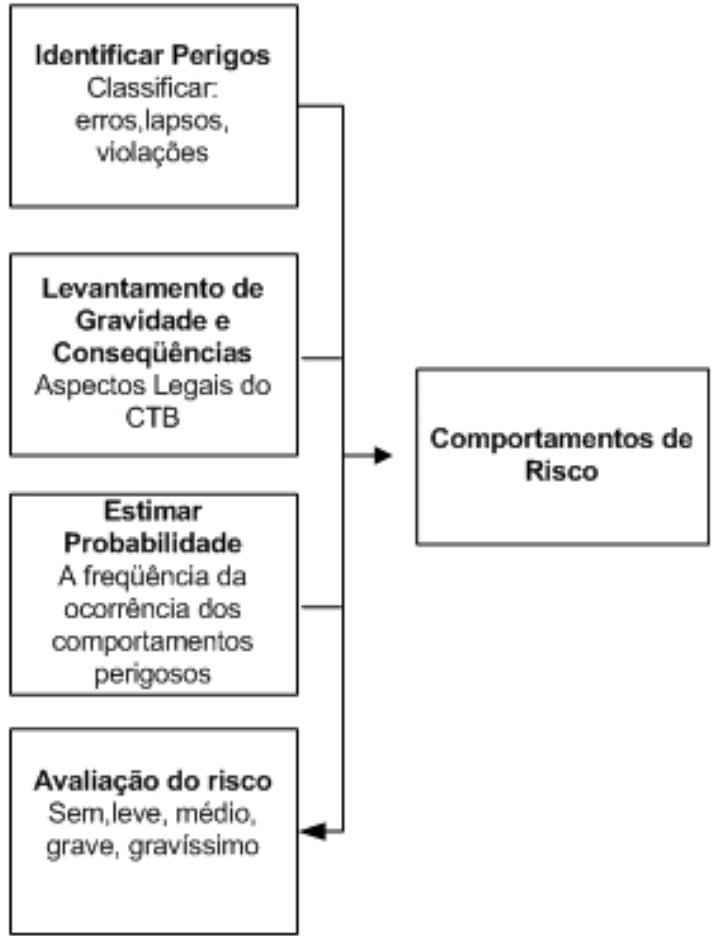

Figura 1: Esquema de avaliação: Comportamento de Risco

\section{Os Comportamentos de risco no trânsito: erros, lapsos e violações}

Como bases teóricas busca-se a conceituação de erros, lapsos e violações comportamentos que representam o risco de um possível envolvimento em acidentes [10,8,7]. Um instrumento de medida desenvolvido pelo grupo de pesquisa do comportamento de motorista - do departamento de psicologia da University of Manchester, aborda estes comportamentos, o Driver Behavior Questionnaire [DBQ], Questionário do comportamento de motoristas [QCM]. A primeira versão, deste instrumento, foi elaborada por Reason et al. [10] contribuindo para a compreensão do comportamento de motoristas e a investigação de como esses comportamentos podem estar relacionados com os acidentes de trânsito.

É a partir dessa concepção que o conceito adotado para o comportamento de risco de condutores, estudo, será considerado pelo cometimento de erros, lapsos e violações, três tipos de comportamentos humanos no trânsito, conceituados e exemplificados no Tabela 2.

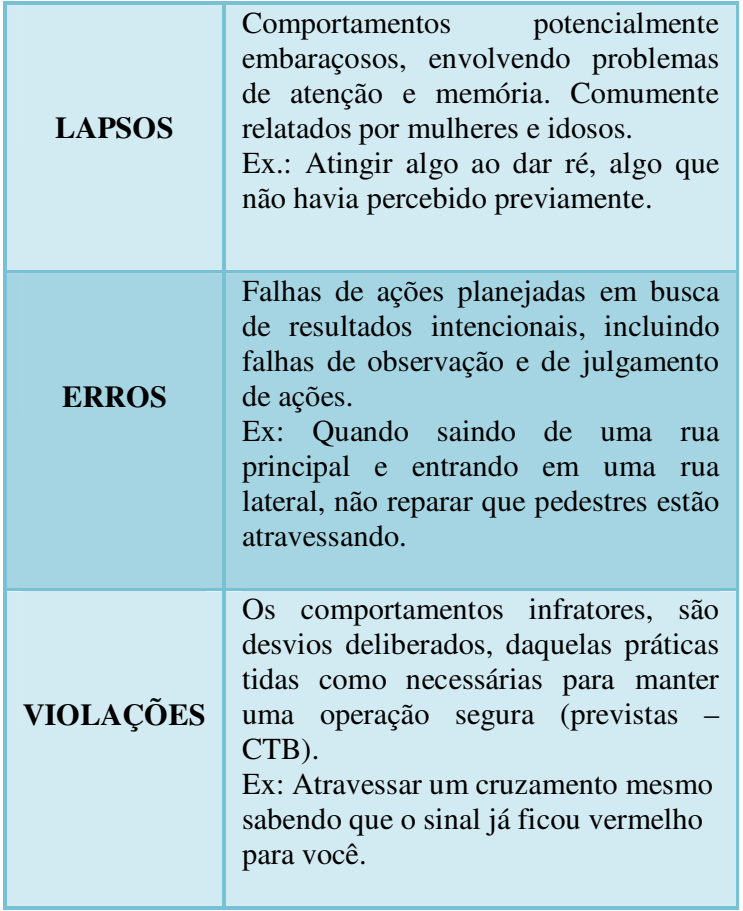

Tabela 2: Definição de Lapsos, Erros e violações.

Fonte: Lawton, et al., 1997, p. 1316; Parker et al., 1998.

Os erros apresentam-se como atitudes mais simples de serem minimizadas, por meio de treinamentos, reciclagens ou o desenvolvimento de formas de comunicação e informação aos condutores. Os erros se encontram nas habilidades aprendidas de conhecimento e informação, bem como nas habilidades e hábitos, como: controle de distância, ultrapassagem, reconhecimento das condições da via (buracos, congestionamentos).

As violações, porém, seriam mais complexas. As intervenções devem se dar por meio de uma mudança de atitude ou de estilo de vida que priorizem a segurança. Se enquadraria nos fatores motivação e nas atitudes dos motoristas consideradas difíceis de serem analisadas, como o comportamento irresponsável que induz à corrida de carro, o orgulho da própria performance ao dirigir e o medo da punição.

Dentro da perspectiva da avaliação dos comportamentos no trânsito e correlacionando com os resultados obtidos em outros países, Bener [3] realizaram um estudo intercultural comparativo sobre a média de violações, erros e lapsos do QCM. Entre os achados de sua amostra está a comparação com a realizada nos Emirados Árabes Unidos (EAU). Entre os países desenvolvidos com pesquisas semelhantes estão a Grã-Bretanha, a Finlândia, a Holanda e a Austrália. Constatou-se que os EAU apresentam um escore significativamente maior de lapsos, erros e violações, quando comparado à Austrália e a outros paí- 
ses europeus. Os homens tiveram um risco significativamente maior de acidentes em comparação com as mulheres dos Emirados Árabes Unidos.

Segundo Hoffmann e González [5], os condutores considerarem suas chances de sofrer um acidente menor do que a de outros. "As estimativas objetivas de risco tenderão a ser consideradas como algo significativo pela maioria dos condutores, somente quando avaliarem seu próprio comportamento" [p.378]. Em muitos casos, a avaliação do próprio comportamento no trânsito só ocorre quando o motorista se salva de um possível acidente ou sofre realmente um. Desta forma, o desempenho do motorista, em um jogo de condução, possa servir como uma forma de alerta sobre os possíveis risco a que este está se submetendo ao dirigir.

\section{Jogos digitais}

A utilização das Tecnologias de Informação no desenvolvimento de jogos pode favorecer o despertar de emoções, atitudes, e habilidades em seus jogadores. Segundo Ribeiro [10], o desenvolvimento de um cenário virtual, através do jogo traz benefícios como: recria cenários de difícil acesso, temporários e perigosos; possibilita criar um espaço virtual localizado e uma diversidade de situações problemas e a construção de situações contextualizadas.

Existe um crescente interesse na utilização de jogos de computador, os quais podem ser empregados com diversas finalidades e estratégias. Backlund et al. [1] distinguem os jogos de diversão dos que denominam como jogos sérios, que possuem um objetivo definido, e não de mera diversão.

As abordagens que permitam a confrontação dos riscos a que o indivíduo se expõe e sujeita-se ao dirigir podem ser uma forma de autoconhecimento e possibilidade de reflexão sobre os mesmos. Para a aprendizagem no trânsito, a possibilidade de criar ambientes com diversidade de estímulos, cenas típicas, situações problema, como um possível acidente, por descuido ao dirigir, em um ambiente controlado, são de grande valor. A simulação de situações em ambientes virtuais, por exemplo, pode propiciar essas experiências, sem os riscos reais.

Segundo Backlund et al. [1], os jogos não são realistas, no sentido integral da condução, mas parecem ter um impacto sobre alguns aspectos da condução de um automóvel. O estudo da utilização desses recursos em jogos e simuladores de condução, portanto, vem auxiliar no desenvolvimento de uma metodologia de avaliação de mo- toristas, como no jogo digital com situações de trânsito proposto.

\subsection{Jogo digital de trânsito}

Conduzir um veículo pode ser considerado uma atividade complexa, na qual muitas variáveis estão interagindo, próprias do condutor, como do meio. Deste modo, os ambientes virtuais favorecem a construção de cenários que possibilitam a simulação de inúmeras situações, que permitam a interação do jogador com o ambiente simulado.

Criar modelos de jogos que propiciem às crianças, aos jovens e adultos outras formas de envolvimento com veículos é importante, oferece aspectos não só de entretenimento, mas questões relevantes a respeito de trânsito e segurança. Atualmente, vem crescendo o investimento nessa área. Os jogos disponibilizados em sites dos DETRANs do país e da EPTC, apresentam atividades como jogos de memória, de habilidades e conhecimentos sobre legislação de trânsito.

Percebe-se, assim, que esse tipo de ambiente possibilita a observação e a classificação das atitudes tomadas frente a situações específicas, tornando-se uma ferramenta útil para a avaliação de comportamentos.

O jogo digital de trânsito proposto, neste artigo, tem fins de avaliação, um jogo sério, destinado a jovens e adultos, com o propósito de monitorar uma série de comportamentos durante um percurso, com várias situações apresentadas. Do ponto de vista educacional, por meio do desempenho do jogador, visa possibilitar o conhecimento do cometimento de comportamentos de risco a que o condutor se encontra suscetível. Também, apresentar as implicações e conseqüências, como pontuação e valores gastos com as infrações cometidas, caso fossem cometidas realmente no trânsito.

Cada situação apresentada no jogo foi baseada em dados apresentados no QCM de erros, lapsos e violações Também foram consideradas informações sobre as infrações mais cometidas, segundo dados estatísticos da Empresa Pública de Transporte e Circulação [EPTC]. As infrações foram classificadas, segundo o Código de trânsito Brasileiro [CTB], em artigo, grupo, pontuação e valor das multas.

Além de verificar a frequiência do comportamento de risco este é avaliado quanto a sua gravidade, ao serem estipuladas pontuações variadas para as atitudes no trânsito, correspondentes a classificação de gravidade estabelecida no CTB. Todas as situações apresentadas durante o jogo são avaliadas como o exemplo demonstrado pela Figura 2: 


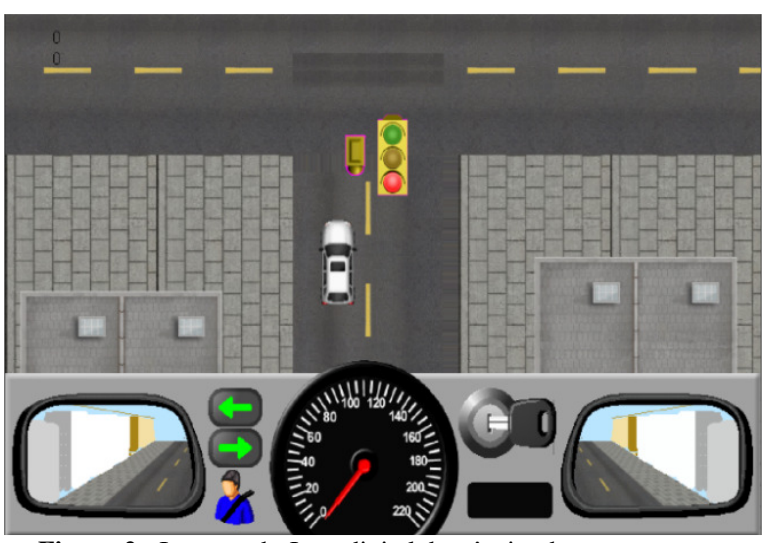

Figura 2: Imagem do Jogo digital de trânsito de um cruzamento com semáforo

Na situação de jogo proposta na Figura 1 a avaliação segue os seguintes critérios:

- Ocorrência de Violação - Atravessar um cruzamento mesmo sabendo que o sinal já ficou vermelho;

- Infração do Art. 208 [CTB] Avançar o sinal vermelho do semáforo ou o de parada obrigatória;

- Grupo - Infração Gravíssima;

- Pontos: 7 pontos e

- Multa: R\$ 191, 54. [2]

Ao final do Jogo é disponibilizado ao jogador o total de sua pontuação a qual pode chegar ao total de 100 pontos. Quanto maior a pontuação, mais elevado é o grau de risco do comportamento, conforme classificação demonstrada na Tabela 4.

\begin{tabular}{|c|c|}
\hline Sem & Não ocorre \\
\hline Leve & Até 19 pontos \\
\hline Médio & $20-47$ pontos \\
\hline Grave & $48-75$ pontos \\
\hline Gravíssimo & $76-100$ pontos \\
\hline
\end{tabular}

comportamento de condutores.

Para a concretização das idéias propostas, nesta versão do jogo digital TransRisco, contou-se com a colaboração da empresa Hope Revolution Programas e Jogos Didáticos Ltda. O jogo foi desenvolvido em Game Maker com a extensão Resource System, o desenvolvimento gráfico em Blender 3D e Gimp e para os efeitos sonoros utilizou-se Audacity. O Jogo é compatível com máquinas
IBM/ PC, sistema operacional Windows/XP/ Vista/7. O Tamanho do Jogo é de 37,97 MB. Como periféricos utilizou-se um Volante com botões e pedais para PC's

\section{Resultados e discussões}

O instrumento para a coleta de dados, sobre o comportamento de risco em condutores, foi o Jogo digital de trânsito desenvolvido. A população estudada foi composta por condutores com habilitação categoria B, em Centros de Formação de Condutores [CFCs] da cidade de Porto Alegre. Participaram até o momento da presente pesquisa, 52 Condutores. Em geral, o jogo era concluído entre 15 e 20 minutos.

Quanto a ocorrência do comportamento de risco, entre os condutores que utilizaram o jogo, percebe-se a prevalência do grau médio de risco conforme os dados apresentados na Figura 3, bem como, um grau leve, que apresenta-se em segundo lugar. Não foram encontrados os extremos, nem para a não ocorrência, nem para o grau mais elevado de risco.

Percebeu-se entre os condutores ao final do jogo a preocupação com sua pontuação e, em compará-la com os demais avaliados. Ao retornarem a sala, principalmente os homens, queriam verificar a pontuação dos demais.

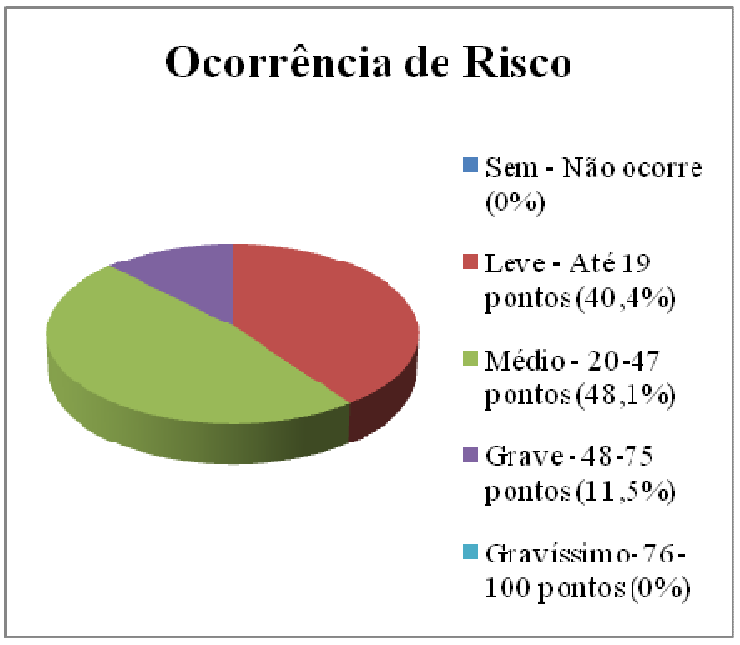

Figura 3: Grafico de ocorrência de risco

Os condutores apresentaram quanto a atravessar o sinal vermelho um percentual de $13,5 \%$ de ocorrência. Um Erro que freqüentemente ocorreu, foi à colisão com o cavalete na pista, o qual despendia uma maior atenção para ser percebido, neste caso $82,7 \%$ dos condutores o atingiram, conforme a Figura 4. 


\section{Atingir o cavalete na pista}

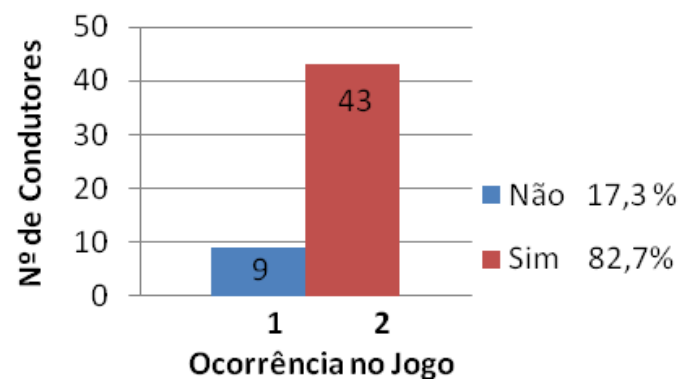

Figura 4: Ocorrência: atingir o cavalete

Com relação a conversão à direita - não reparar que pedestres estão atravessando, apresentou um índice elevado de condutores atentos, em $96,2 \%$ dos casos os pedestres foram percebidos, não ocorrendo incidentes.

Referente a sinalização de intenção e de saída de vaga de estacionamento, ambos tiveram a mesma percentagem, $84,6 \%$ não cometeram a infração, sinalizando a manobra corretamente, conforme Figura 5.

\section{Não sinalizar a intenção de estacionar}

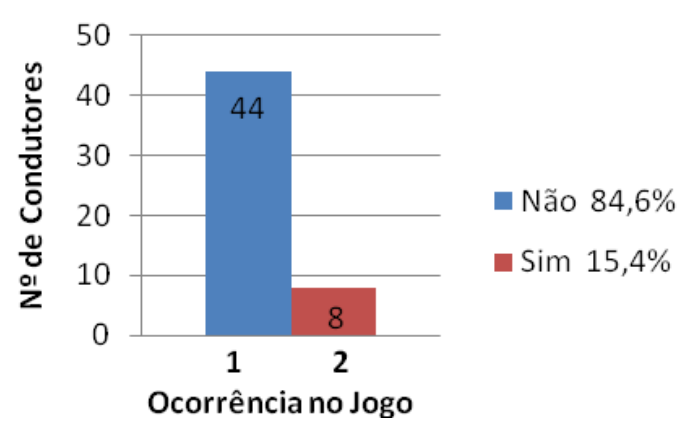

Figura 5: Gráfico de sinalização de manobras.

Com relação ao limite de velocidade, foram apresentadas três situações diferentes, que caracterizaram comportamentos distintos. Primeiramente em uma rua residencial, limite $40 \mathrm{Km}-33,8 \%$ excederam a velocidade. Depois acrescentou-se um celular e o som deste tocando, limite $60 \mathrm{~km}-40,4 \%$ exederam o limite. Por último, apenas apresentou-se a sinalização de $60 \mathrm{~km}$ 15,4\% excederam. Evidencia-se que uma distração como o celular tocando, ocasiona alteração no comportamento de controle de velocidade, a atenção dispensada ao telefone, ampliou o percentual de desrespeito ao limite estabelecido no jogo, situação ilistrada na Figura 6. Quanto a atender ao telefone $25 \%$ dos motoristas atende- ram e $75 \%$ não atenderam, no entanto alguns comentaram que sabiam ser errado, mas em raras situações atendiam.



Figura 6: Controle de velocidade e Celular.

Outro fator significativo foi apresentado em relação a sinalização de PARE, em 44,2\% dos casos os condutores atravessaram o cruzamento sem respeitar a sinalização. $\mathrm{O}$ desrespeito a parada obrigatória é considerada uma infração gravíssima pelo CTB e obteve um percentual elevado de ocorrências. Situação ilustrada na Figura 7.

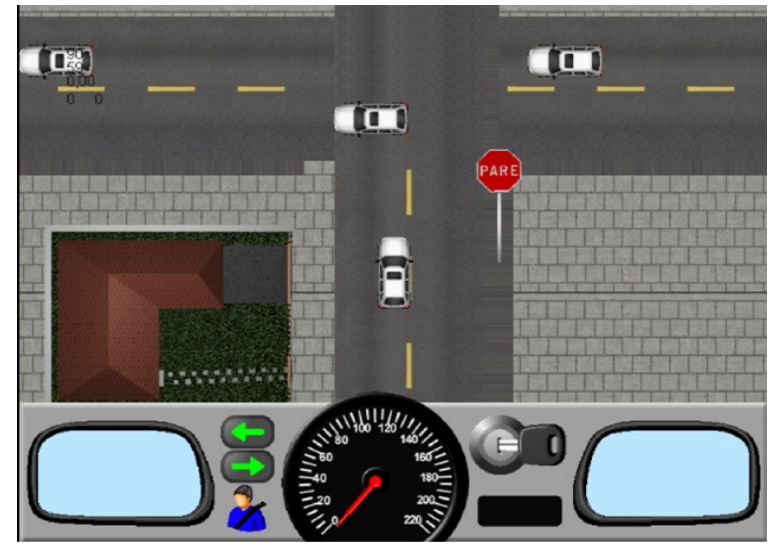

Figura 7: Sinalização de PARE

Quanto ao uso do sinto de segurança, deixar de utilizá-lo apresentou um percentual elevado, conforme dados apresentados na Figura 8. 


\section{Deixar de acionar o cinto}

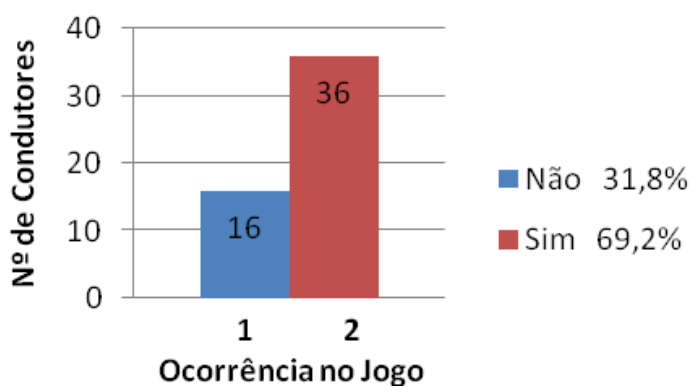

Figura 8: Deixar de acionar o cinto de segurança

Dos condutores $69,2 \%$ deixaram de acionar o cinto e $31,8 \%$ o acionou. Entretanto, deve-se destacar, que esta situação é apresentada inicialmente, momento de maior ansiedade dos jogadores e a forma de acionamento não aproxima-se muito da convencional, em relação a movimentação para colocar o cinto. O jogador deve acioná-lo por um botão no volante do jogo. Estes aspectos podem ter interferido no resultado, no entanto, os condutores mais atentos verificavam inicialmente, que deveriam colocar o cinto.

Outras condutas como atravessar o sinal vermelho, não perceber pedestres em cruzamentos, obtiveram escores baixos. Finalmente, deve-se considerar que os comportamentos de risco apresentados pelos condutores, podem atingir a todos os usuários das vias públicas, tanto pedestres, ciclistas e outros condutores. Sendo a conduta frente ao volante importantíssima de ser avaliadas e repensadas pelos condutores.

\section{Conclusão}

Este estudo apresenta um breve panorama das condutas apresentadas pelos motoristas, frente a situações de trânsito. Observam-se vários comportamentos de risco, fatores precursores de risco para acidentes.

Comportamentos arraigados de desrespeito às normas de trânsito são complexos e exigem como estratégias de prevenção fiscalizações constantes, punições e ações educativas. Desta forma, possibilitar que o motorista se confronte com seu comportamento, um feed-back a respeito de sua conduta ao volante, possa servir para a tomada de consciência de sua forma de dirigir.

Deve-se observar que a aplicação de um jogo digital de trânsito, possui certas limitações, em reproduzir fide- dignamente a realidade, no entanto, apresenta situações típicas de trânsito e propicia a tomada de decisão do jogador, testa conhecimentos sobre a legislação, atenção, dentre outros fatores. Os resultados podem contribuir para traçar perfis de condutores, avaliar as principais deficiências, ou ocorrências no trânsito, que podem nortear campanhas, ações e medidas educativas. Finalmente, propiciar subsídios que visem diminuir os comportamentos de risco e propiciem uma maior segurança no trânsito.

Os resultados coletados, inicialmente, nas aplicações do jogo em condutores de CFCs, de Porto Alegre, demonstram que as infrações relatadas pela EPTC como mais freqüentes no trânsito, correspondem com os primeiros dados adquiridos sobre o comportamento de condutores no Jogo. Destacando-se, o excesso de velocidade e o uso de celular como os comportamentos de risco mais apresentados pelos jogadores.

Espera-se que o instrumento de avaliação, proposto, venha a contribuir em Centro de formação de condutores (CFCs), treinamentos corporativos, cursos, pesquisas e em outras aplicabilidades, além de colaborar para o desenvolvimento de trabalhos de fiscalização e educação para o trânsito. Constatou-se que os resultados despertam a competição entre os condutores, neste caso, pela melhor conduta, esta pode tornar-se uma estratégia que possa produzir resultados relevantes, principalmente em empresas. Como próxima meta, seria aprimorar o Jogo para 3D e desenvolver um ambientes físicos, que aproxime-se ou reproduza o interior de um veículo, para propiciar mais realismo a ferramenta.

A segurança no trânsito partiria da conscientização, do treinamento de ações corretas, da formulação de ações preventivas e de fiscalização. Pesquisas na área de educação e segurança no trânsito são imprescindíveis, pois os custos com acidentes de trânsito são altos para a sociedade, sem contar as perdas de vidas irreparáveis. O desenvolvimento de projetos para a condução em estradas, com motoristas profissionais e o aprimoramento tecnológico com simuladores, possibilitaram atingir uma gama maior de condutores e aperfeiçoar as ferramentas utilizadas nesta área.

\section{Agradecimentos}

Ao apoio do CNPq.

\section{Referências}

[1] Backlund. P, H. Engström \& outros. Games for traffic education: An experimental study of a 
game-based driving simulator. Simulation \& Gaming, May, 19, 2008.

[2] Brasil. Código de Trânsito Brasileiro. Disponível em:

http://www.planalto.gov.br/ccivil_03/Leis/L950 3.htm Acesso em: 20 nov. 2007.

[3] Bener, A., D. Crundall., et al. Driving behaviour, lapses, errors and violations on the road: United Arab Emirates study." Advances in Transportation Studies an international Journal", $12,2007$.

[4] Diógines. Indicadores de Desempenho no Gerenciamento da Segurança Viária. Dissertação Mestrado Acadêmico. Engenharia de Produção UFRGS. Área de Transportes, 2004.

[5] Hoffmann. M, L. González. Acidentes de trânsito e fator humano. In: Hoffmann, M.H (org). Comportamento humano no trânsito. São Paulo: Casa do psicólogo, 2003. p. 377-391.

[6] IPEA. Impactos sociais e econômicos dos acidentes de trânsito nas rodovias brasileiras Relatório Final. Brasília: IPEA/DENATRAN /ANTP, 2006. Disponível em: http://www.ipea.gov.br/default.jsp. Acesso em 20 set. 2007

[7] Lawton. R, D. Parker \& outros. The Role of Affetc in Predicting Social Behaviours: The Case of Road Traffic Violations, Journal of Applied Social Psychology, v. 27, n¹ 4, 1997. p. 1258- 1276.

[8] Parker. D, T. Lajunen, S. Stradling. Stephen. Attitudinal Predictors of interpersonally aggressive violations on the road. Transportation Research Part F: Traffic and Transport Psychology, v. 1,1998, p. $1-14$.

[9] Pirito, Ma. Considerações sobre o Motorista Idoso. São Paulo: ABRAMET. p. 25-27, 1999.

[10] Reason, J. T.; Manstead, A. S. R.; Stradling, S.; Baxter, J.; \& Campbell, K. Errors and violations on the roads: a real distinction. Ergonomics, v. 33, 1990. p. 1315-1332.

[11] Ribeiro. L, Timm. M, Zaro. M. Modificações em jogos digitais e seu uso potencial como tecnologia educacional para o ensino de engenharia". RENOTE - Revista Novas Tecnologias na Edu- cação, CINTED-UFRGS. v. 4 nº 1, Julho, 2006.

[12] São Paulo. Prefeitura municipal. Infrações ligadas a comportamento lideram balanço de multas, 2008. Disponível em :

http://www.prefeitura.sp.gov.br/portal/a_cidade/ noticias/index.php? $\mathrm{p}=21547$. Acesso em: abril de 2008.

[13] Vanderbilt. T,. J. E. M. Xavier. Uma Estrutura para a Construção de Sistemas de Controle Baseados em Agentes para Robôs Móveis. Dissertação de Mestrado, Universidade Federal do Espírito Santo, Novembro 1996. 